\title{
Submicroscopic Plasmodium falciparum Infections Before and After Sulfadoxine-Pyrimethamine and Artesunate Association Treatment in Dienga, Southeastern Gabon
}

\author{
Fousseyni S. Touré, PhD; Jérôme Mezui-Me-Ndong, MS; Odile Ouwe-Missi-Oukem-Boyer, PhD; \\ Benjamin Ollomo, PhD; Dominique Mazier, MD, PhD; and Sylvie Bisser, MD, PhD
}

\begin{abstract}
Background: It has been shown that Plasmodium falciparum submicroscopic infections (SMI) can contribute to malaria-associated anemia as well as to cerebral malaria. Polymerase chain reaction (PCR) assays are usually used as an alternative to microscopy in detecting subpatently infected individuals.
\end{abstract}

Objectives: The main objective of this study was to investigate the occurrence of SMI before and after a suppressive antimalarial treatment in the population of the village of Dienga in Gabon.

Methods: Nested PCR was used to detect SMI and to determine genotypes.

Results: The prevalence rates of SMI were $13.67 \%$ (38/278) at day 0 and $8.99 \%(25 / 278)$ at day I 4 after sulfadoxine-pyrimethamine-artesunate treatment. Genotype analysis of two polymorphic regions of the merozoite surface protein (MSP)-I block 2, MSP-2 and a dimorphic region of the erythrocyte binding antigen (EBA- I 75) revealed that as many as $88 \%(22 / 25)$ of SMI detected after treatment were completely new alleles, indicating either previously sequestered parasites or newly acquired infections.

Conclusion: These results demonstrate the usefulness of sulfadoxine-pyrimethamine-artesunate association treatment in the population of Dienga and confirmed early parasite genotype change after a suppressive antimalarial treatment in endemic areas.

Keywords: Dienga, Gabon; Endemic area; PCR; Prevalence; Submicroscopic Plasmodium falciparum; Sulfadoxine-pyrimethamine-artesunate

$\mathrm{T}$ he diagnosis of Plasmodium falciparum infections based on microscopic examination of stained blood smears remains to date the most practical and reliable means for detecting parasites in blood samples. ${ }^{1}$ However, the sensitivity of this technique decreases with malaria parasite density in blood. ${ }^{2}$ When parasitemia is low, during mixed infections, after drug treatment or during the chronic phase of the infection, diagnosis by microscopy requires long periods of observation and experienced microscopists. ${ }^{3}$ Therefore, polymerase chain reaction (PCR) assays have been used as an alternative to microscopy because of their high sensitivity and specificity. ${ }^{4}$ Interestingly, since the work of Jarra and Snounou ${ }^{5}$ in 1998, it has been shown that malaria parasite DNA is cleared very quickly from the blood circulation and that a positive PCR amplification is mainly associated with the presence of viable parasites and represents submicroscopic infections (SMI).

While it has been shown in endemic areas that P. falciparum SMI contribute to malaria-associated anemia and inflammation, ${ }^{6}$ the clinical and epidemiological relevance of such infections remains unclear. However, more recently it has been documented that cerebral malaria is frequently associated with SMI in semi-immune individuals. ${ }^{7}$

The evidence for subpatent parasitemia detectable by PCR, as well as a rapid turnover of $P$. falciparum isolates in infected individuals have been previously reported, 8,9 Nevertheless, the influence of antimalarial treatment, such as sulfadoxine-pyrimethamine-artesunate association on the occurrence of SMI, has not been investigated.
Reprint Requests: Fousseyni S. Touré, PhD, Centre International de Recherches Médicales de Franceville (CIRMF), BP 769 Franceville, Gabon. Tel: 00 24I 677092; Fax: 00 24I 677095; E-mail: fousseyni@yahoo.fr
Received: January 25, 2006

Revised: May 10, 2006

Accepted: June 20, 2006
Grant Support: CIRMF is supported by the government of Gabon, Total Gabon and French Ministry of Foreign Affairs. 
A prospective longitudinal study was undertaken in Dienga to assess whether hepatitis viruses $\mathrm{B}$ or $\mathrm{C}$ infection may influence the delay of emergence of asexual malarial parasites in the blood after suppressive treatment. This study has provided an opportunity to determine the prevalence rates of SMI before and after sulfadoxine-pyrimethamine-artesunate combination treatment (Ouwe-Missi-Oukem-Boyer et al, manuscript in preparation).

\section{Materials and Methods}

\section{Study Site and Subjects}

This study was carried out in Dienga (Ogooué Lolo Province), a village in southeastern Gabon where $P$. falciparum malaria is highly endemic with a perennial mode of transmission and some seasonal fluctuation. ${ }^{10,11}$ Preliminary data from studies done in this area reveal that the transmission of $P$. falciparum is predominantly due to Anopheles gambiae, with an entomological infection rate of 100 infective bites per human per year. ${ }^{11}$

Informed consent was obtained from 278 individuals or from their parents. Participants ranged in age from 14 to 75 years. The study was approved by the ethics committee of the International Centre for Medical Research of Franceville (CIRMF) Gabon, the Governor of the Province and the village authorities, and performed in accordance with the guidelines for human experimentation in clinical research of the Ministry of Public Health and Population of Gabon (Libreville).

\section{Blood Sample Collection}

On day 0, peripheral venous blood samples were obtained from each individual and collected in EDTA sterile tubes for malaria diagnosis. A thick blood smear was made and three drops of blood were also deposited on Serobuvard calibrated pre-punched paper disks (LDA 22 , Zoopole, Ploufragan, France). ${ }^{12}$ After 4 hours at room temperature, dried blood spots were put in envelopes, transported to CIRMF and stored in an air-conditioned room until use. Thick peripheral blood films were stained with Giemsa and examined by two microscopists following standard, quality-controlled procedures. Parasite load was expressed as the number of asexual forms of $P$. falciparum/ $\mu$ l of blood, assuming an average leukocyte count of $8000 / \mu 1$. After sampling, all the 278 individuals were treated using a single dose of sulfadoxine-pyrimethamine $(25 \mathrm{mg} / \mathrm{kg} /$ day and $1.25 \mathrm{mg} / \mathrm{kg} / \mathrm{day}$, respectively) given on day 0 and artesunate $(4 \mathrm{mg} / \mathrm{kg} /$ day $)$ given on days 0-2 (Ouwe-Missi-Oukem-Boyer et al, manuscript in preparation).

Blood was collected from each individual on day 14 by finger prick. The blood was absorbed onto Serobuvard discs. Thick blood smears were also made and staining for $P$. falciparum proceeded as described above.

\section{DNA Extraction}

DNA templates were extracted using dried blood spots as previously described. ${ }^{13}$ Each dried blood spot was placed in 1 $\mathrm{ml}$ of phosphate buffered saline (PBS) containing $0.5 \%$ saponin and incubated overnight at $4^{\circ} \mathrm{C}$. The resulting brown solution was replaced with $1 \mathrm{ml}$ PBS and incubated for an additional $15-30$ minutes at $4^{\circ} \mathrm{C}$. After this incubation, $200 \mu \mathrm{l}$ of 5\% Chelex 100 (Bio-Rad Laboratories, CA) was placed in clean tubes and heated at $100^{\circ} \mathrm{C}$ in a water bath. The disks were removed from the PBS and placed in the preheated 5\% Chelex 100, vortexed at high speed for 30 seconds and placed in a water bath at $100^{\circ} \mathrm{C}$ for 10 minutes with gentle agitation. Samples were then centrifuged at $10,000 \times \mathrm{g}$ for 2 minutes, and the supernatant removed and centrifuged as before. The supernatant was then collected into a clean tube and used for PCR immediately or stored at $20^{\circ} \mathrm{C}$ until use.

\section{DNA Amplification for P. falciparum Diagnosis}

Five microliters of the Chelex supernatants were amplified using a Perkin Elmer thermal cycler in a $50 \mu$ l reaction containing $1 \mathrm{x}$ PCR buffer as supplied by the manufacturer (200 mM Tris-HCl, pH 8.7, $100 \mathrm{mM} \mathrm{KCl,} 100 \mathrm{mM}\left(\mathrm{NH}_{4}\right)_{2}$ $\mathrm{SO}_{4}, 20 \mathrm{mM} \mathrm{MgSO} 4,1 \%$ Triton-X 100, $1 \mathrm{mg} / \mathrm{ml}$ of bovine serum albumin), $200 \mu \mathrm{M}$ each of dATP, dCTP, dGTP and dTTP, $1 \mu \mathrm{M}$ of each primer and 1 unit of Taq DNA polymerase (Invitrogen, Cergy Pantoise, France). PCR and nested PCR were carried out as previously documented 4 to amplify the $P$. falciparum small subunit ribosomal RNA gene. After amplification, $10 \mu \mathrm{l}$ of each nested PCR product was mixed with $1 \mu \mathrm{l}$ of loading dye $(0.25 \%$ bromophenol blue, $0.25 \%$ xylene cyanol and $40 \% \mathrm{w} / \mathrm{v}$ sucrose in water) and analyzed by electrophoresis on a $1.5 \%$ agarose gel. The gel was stained with ethidium bromide and the DNA was visualized and photographed under ultraviolet light.

\section{DNA Amplification for P. falciparum Genotyping}

Before genotype determination, five separate, randomly chosen, nested PCR products were sequenced. The alignment of these sequences showed that they were $100 \%$ identical to the original sequence of the $P$. falciparum small subunit ribosomal RNA gene (data not shown).

Genotypes of the parasite population were analyzed on paired primary and post treatment samples. Block 2 of merozoite surface protein (MSP)-1, block 3 of MSP-2, and erythrocyte binding antigen (EBA)-175 were amplified by nested PCR as previously reported. ${ }^{14-16}$ Briefly, after amplification, $10 \mu \mathrm{l}$ of each nested PCR product were analyzed by electrophoresis on a $1.5 \%$ agarose gel. PCR-positive samples at day 0 and day 14 were processed concomitantly and the bands compared. Identical bands were classified as treatment failure, while nonidentical bands were considered new infections.

\section{Results}

At the start of the study (day 0), 278 individuals ranging in age from 14 to 75 years were examined. After the standard microscopic examination, $20(7.2 \%)$ specimens were positive 
Table 1. Comparison of $P$. falciparum submicroscopic infections (SMI) before and after sulfadoxine-pyrimethamine and artesunate association treatment.

\begin{tabular}{lccccc}
\hline Day & Total samples & Blood smear positive & Blood smear negative & PCR positive (SMI) & PCR negative \\
\hline 0 & 278 & $20^{*}(7.2 \%)$ & $258(92.8 \%)$ & $38(13.67 \%)$ & $220(79.13 \%)$ \\
14 & 278 & $0(0 \%)$ & $278(100 \%)$ & $25(8.99 \%)$ & $230(82.73 \%)$ \\
\hline
\end{tabular}

*, not tested by polymerase chain reaction (PCR).

for $P$. falciparum. The remaining 258 individuals with negative blood smears were assessed by nested PCR; 38 of these samples tested positive for P. falciparum. Overall, the prevalence of $P$. falciparum infection (detected by standard microscopy and PCR) before treatment was $20.8 \%$ (58/278, table 1). Among those infections, SMI were the most prevalent (13.67\%).

After treatment, microscopic examination was repeated on blood samples from the 278 individuals, but all were negative for P. falciparum. By using a nested PCR assay, 25/278 (8.99\%) blood samples tested positive for P. falciparum on day 14 and, therefore, represent the occurrence of SMI posttreatment (table 1). Among these 25 SMIs, nine were detected only during posttreatment, 6 were thick blood smear positive at day 0 , and the remaining 10 were detected at both pre- and posttreatment (table 2). The SMIs detected only during posttreatment (9) represent new SMI.

Genotyping was done on the 6 samples that were positive by microscopic evaluation on day 0 and on the 10 SMI that were detected both pre- and posttreatment. The results showed a predominance of the K1 and FCR-3 genotypes from MSA-1 and EBA-175 genes, respectively. Interestingly, 13 of these 16 $P$. falciparum isolates, including the 6 blood smear positive samples at day 0 , showed completely new alleles. The remaining 3 SMI (12\%) presented identical P. falciparum strains during pre- and posttreatment, as characterized by identical patterns for MSA-1, MSA-2 and EBA-175 alleles (table 2).

Twenty-two of 25 (88\%) SMI detected after treatment were probably new infections. This includes the 9 SMI detected only during posttreatment for which genotypes have not been determined.

Overall, $95 \%$ of $P$. falciparum isolates detected at day 0 (blood smear and PCR) were killed by sulfadoxine-pyrimethamineartesunate association treatment. This included all blood smear positive samples and 35 of 38 SMI.

\section{Discussion}

The main objective of this study was to investigate the occurrence of $P$. falciparum SMI before and after a suppressive antimalarial treatment in the population of the Dienga village in Gabon. This study was the first to focus only on SMI during pre- and posttreatment in an endemic area of central Africa. Our data show that K1 and FCR-3 genotypes from MSA-1 and EBA-175 genes, respectively, were predominantly encountered. These findings are consistent with data reported by Kun et al. ${ }^{17}$ Our results confirmed, first, that microscopically detectable $P$. falciparum parasitemia in peripheral blood is a poor indicator of active infection and second, the persistence of SMI in endemic areas as previously demonstrated. ${ }^{8,9,18}$ The prevalence of SMI in Dienga was $8.99 \%$ after only 2 weeks of treatment suggesting that the entire study population may be infected at least once in 6 months.

Interestingly, these results demonstrated the usefulness of sulfadoxine-pyrimethamine and artesunate association in the treatment of uncomplicated $P$. falciparum infections, since all blood smear positive individuals were aparasitemic at day 14 posttreatment. Furthermore, all samples were negative by PCR at day 14 except those representing new infections. Although our study was not designed to investigate the efficacy of sulfadoxine-pyrimethamine plus artesunate, our results indicate a high cure rate of this combination in Dienga. However, this treatment does not prevent the early appearance of new infections. Twenty-two of 25 SMI (88\%) detected in posttreatment were completely new parasite populations that had not been detected at day 0 . Such changes in P. falciparum genotypes within individual infections could occur when PCR fails to detect either the minority parasite that is drug resistant in multiple genotype infections or previously sequestered parasites that are not present in the peripheral blood at day 0 of sampling. ${ }^{19-21}$ However, since these individuals live in a perennial transmission area with continuous exposure, it is more likely that they were infected with new parasite populations that have emerged from the liver. This later hypothesis is consistent with previous reports from other malaria endemic countries of Africa. ${ }^{9,19,22}$

In this study, 3 SMI presented with the identical P. falciparum strain during pre- and posttreatment, as characterized by an identical pattern for MSA-1, MSA-2 and EBA-175 alleles. These 3 SMI, of an overall 58 P. falciparum infections (5.1\%), may represent genetically similar, but new infections occurring in the posttreatment period or previously sequestered parasites. Alternatively, it is also possible that the 3 SMI treatment failures may be due to the drug resistant $P$. falciparum strains. This is not surprising as the clinical and parasitological failures in artesunate plus sulfadoxine-pyrimethamine treatment of uncomplicated malaria have been recently reported in Sudan. ${ }^{23,24}$ 
Table 2. Comparison of genotype profiles of $P$. falciparum isolates during pre-treatment and post-treatment using sulfadoxinepyrimethamine and artesunate association.

\begin{tabular}{|c|c|c|c|c|c|c|}
\hline \multirow{3}{*}{ Isolates } & \multicolumn{3}{|c|}{ Day 0 (pretreatment) } & \multicolumn{3}{|c|}{ Day 14 (posttreatment) } \\
\hline & \multicolumn{3}{|c|}{ Genotypes } & \multicolumn{3}{|c|}{ Genotypes } \\
\hline & MSA-1 & MSA-2 & EBA-175 & MSA-1 & MSA-2 & EBA-175 \\
\hline 29 & $\mathrm{~K} 1$ & 3D7 & FCR3 & $\mathrm{K} 1$ & FC27 & CAMP \\
\hline 132 & $\mathrm{~K} 1$ & 3D7 & FCR3 & K1 Ro33 & $\mathrm{FC} 27$ & FCR3 \\
\hline $156^{*}$ & K1/Ro33/Mad20 & FC27 & FCR3/CAMP & $\mathrm{K} 1$ & 3D7 & FCR3 \\
\hline 217 & K1 & FC27 & FCR3 & K1 & FC27 & FCR3 \\
\hline $271^{*}$ & $\mathrm{~K} 1$ & $\mathrm{FC} 27$ & FCR3 & $\mathrm{K} 1$ & $3 \mathrm{D} 7$ & FCR3 \\
\hline 329 & K1/Mad20 & 3D7 & FCR3/CAMP & K1 & 3D7 & FCR3 \\
\hline 873 & K1 & 3D7 & FCR3 & K1 & 3D7 & FCR3 \\
\hline $266^{*}$ & K1/Ro33 & - & CAMP & Ro33 & unassigned & FCR3 \\
\hline 363 & Ro33 & 3D7 & - & Ro33 & FC27 & - \\
\hline $714^{*}$ & Mad20 & unassigned & FCR3 & Mad20 & $\mathrm{FC} 27$ & FCR3 \\
\hline 88 & Ro33 & 3D7 & FCR3 & $\mathrm{K} 1$ & unassigned & FCR3 \\
\hline 129 & $\mathrm{~K} 1$ & $\mathrm{FC} 27$ & - & unassigned & 3D7 & - \\
\hline $201^{*}$ & Unassigned & unassigned & CAMP & Mad20 & 3D7 & FCR3 \\
\hline 245 & K1/Mad20 & 3D7 & CAMP & - & - & FCR3 \\
\hline $337^{*}$ & Unassigned & - & FCR3/CAMP & $\mathrm{K} 1$ & - & FCR3/CAMP \\
\hline 875 & Unassigned & 3D7 & CAMP & Ro33 & - & FCR3 \\
\hline
\end{tabular}

*, aparasitemic patients at pretreatment stage.

Isolates and corresponding genotypes in bold type indicate isolates with identical allele patterns pre- and posttreatment.

In summary, the occurrence of $P$. falciparum SMI was investigated in 278 individuals before and after sulfadoxinepyrimethamine-artesunate treatment. The results confirmed both the usefulness of such combined treatment and the persistence of SMI in endemic areas.

\section{Acknowledgments}

We are grateful to the people of Dienga for participating in this study, and to the staff of the CIRMF Parasitology Unit for their assistance with this research project.

\section{References}

1. Warhurst DC, Williams JE. ACP Broadsheet no 148. July 1996. Laboratory diagnosis of malaria. J Clin Pathol 1996;49:533-538.

2. Iqbal J, Sher A, Hira PR, Al-Owaish R. Comparison of the OptiMAL test with PCR for diagnosis of malaria in immigrants. J Clin Microbiol 1999;37:3644-3646.

3. Kain KC, Keystone JS. Malaria in travelers. Epidemiology, disease, and prevention. Infect Dis Clin North Am 1998;12:267-284.
4. Snounou G, Viriyakosol S, Zhu XP, Jarra W, Pinheiro L, do Rosario VE, Thaithong S, Brown KN. High sensitivity of detection of human malaria parasites by the use of nested polymerase chain reaction. Mol Biochem Parasitol 1993;61:315-320.

5. Jarra W, Snounou G. Only viable parasites are detected by PCR following clearance of rodent malarial infections by drug treatment or immune responses. Infect Immun 1998; 66:3783-3787.

6. Mockenhaupt FP, Ulmen U, von Gaertner C, Bedu-Addo G, Bienzle U. Diagnosis of placental malaria. J Clin Microbiol 2002;40:306-308.

7. Giha HA, A-Elbasit IE, A-Elgadir TM, Adam I, Berzins K, Elghazali G, Elbashir MI. Cerebral malaria is frequently associated with latent parasitemia among the semi-immune population of eastern Sudan. Microbes Infect 2005;7:1196-1203.

8. Bottius E, Guanzirolli A, Trape JF, Rogier C, Konate L, Druilhe P. Malaria: even more chronic in nature than previously thought; evidence for subpatent parasitaemia detectable by the polymerase chain reaction. Trans R Soc Trop Med Hyg 1996;90:15-19. 
9. Daubersies P, Sallenave-Sales S, Magne S, Trape JF, Contamin H, Fandeur T, Rogier C, Mercereau-Puijalon O, Druilhe P. Rapid turnover of Plasmodium falciparum populations in asymptomatic individuals living in a high transmission area. Am J Trop Med Hyg 1996;54:18-26.

10. Deloron P, Ringwald P, Luty AJ, Renaut A, Minh TN, Mbessy JR, Millet P. Relationships between malaria prevalence and malaria-related morbidity in school children from two villages in central Africa. Am J Trop Med Hyg 1999;61:99-102.

11. Elissa N, Migot-Nabias F, Luty A, Renaut A, Toure F, Vaillant M, Lawoko M, Yangari P, Mayombo J, Lekoulou F, Tshipamba P, Moukagni R, Millet P, Deloron P. Relationship between entomological inoculation rate, Plasmodium falciparum prevalence rate, and incidence of malaria attack in rural Gabon. Acta Trop 2003;85:355-361.

12. Ouwe-Missi-Oukem-Boyer ON, Hamidou AA, Sidikou F, Garba A, Louboutin-Croc JP. The use of dried blood spots for HIV-antibody testing in Sahel. Bull Soc Pathol Exot 2005;98:343-346.

13. Plowe CV, Djimde A, Bouare M, Doumbo O, Wellems TE Pyrimethamine and proguanil resistance-conferring mutations in Plasmodium falciparum dihydrofolate reductase: polymerase chain reaction methods for surveillance in Africa. Am J Trop Med Hyg 1995;52:565-568.

14. Snounou G, Zhu X, Siripoon N, Jarra W, Thaithong S, Brown $\mathrm{KN}$, Viriyakosol S. Biased distribution of msp1 and msp2 allelic variants in Plasmodium falciparum populations in Thailand. Trans R Soc Trop Med Hyg 1999;93:369-374.

15. Toure FS, Mavoungou E, Ndong JM, Tshipamba P, Deloron P. Erythrocyte binding antigen (EBA-175) of Plasmodium falciparum: improved genotype determination by nested polymerase chain reaction. Trop Med Int Health 2001;6:767-769.

16. Toure FS, Bisseye C, Mavoungou E. Imbalanced distribution of Plasmodium falciparum EBA-175 genotypes related to clinical status in children from Bakoumba, Gabon. Clin Med Res 2006;4:7-11.

17. Kun JF, Schmidt-Ott RJ, Lehman LG, Lell B, Luckner D, Greve B, Matousek P, Kremsner PG. Merozoite surface antigen 1 and 2 genotypes and rosetting of Plasmodium falciparum in severe and mild malaria in Lambarene, Gabon. Trans R Soc Trop Med Hyg 1998;92:110-114.

18. Mayengue PI, Rieth H, Khattab A, Issifou S, Kremsner PG, Klinkert MQ, Ntoumi F. Submicroscopic Plasmodium falciparum infections and multiplicity of infection in matched peripheral, placental and umbilical cord blood samples from Gabonese women. Trop Med Int Health 2004;9:949-958.

19. Sutherland CJ, Alloueche A, Curtis J, Drakeley CJ, Ord R, Duraisingh M, Greenwood BM, Pinder M, Warhurst D, Targett GA. Gambian children successfully treated with chloroquine can harbor and transmit Plasmodium falciparum gametocytes carrying resistance genes. Am J Trop Med Hyg 2002;67:578-585.

20. Kassberger F, Birkenmaier A, Khattab A, Kremsner PG, Klinkert MQ. PCR typing of Plasmodium falciparum in matched peripheral, placental and umbilical cord blood. Parasitol Res 2002;88:1073-1079.

21. Schleiermacher D, Le Hesran JY, Ndiaye JL, Perraut R, Gaye A, Mercereau-Puijalon O. Hidden Plasmodium falciparum parasites in human infections: different genotype distribution in the peripheral circulation and in the placenta. Infect Genet Evol 2002;2:97-105.

22. Happi CT, Gbotosho GO, Sowunmi A, Falade CO, Akinboye DO, Gerena L, Kyle DE, Milhous W, Wirth DF, Oduola AM Molecular analysis of Plasmodium falciparum recrudescent malaria infections in children treated with chloroquine in Nigeria. Am J Trop Med Hyg 2004;70:20-26.
23. van den Broek I, Amsalu R, Balasegaram M, Hepple P, Alemu E, Hussein el B, Al-Faith M, Montgomery J, Checchi F. Efficacy of two artemisinin combination therapies for uncomplicated falciparum malaria in children under 5 years, Malakal, Upper Nile, Sudan. Malar J 2005;4:14.

24. Elamin SB, Malik EM, Abdelgadir T, Khamiss AH, Mohammed MM, Ahmed ES, Adam I. Artesunate plus sulfadoxine-pyrimethamine for treatment of uncomplicated Plasmodium falciparum malaria in Sudan. Malar J 2005;4:41.

\section{Author Affiliations}

Fousseyni S. Touré, PhD, Centre International de Recherches Médicales de Franceville (CIRMF), BP 769 Franceville, Gabon.

\section{Jérôme Mezui-Me-Ndong, MS, Centre International de Recherches Médicales de Franceville (CIRMF), BP 769 Franceville, Gabon.}

Odile Ouwe-Missi-Oukem-Boyer, PhD, Centre International de Recherches Médicales de Franceville (CIRMF), BP 769 Franceville, Gabon.

Benjamin Ollomo, PhD, Centre International de Recherches Médicales de Franceville (CIRMF), BP 769 Franceville, Gabon.

Sylvie Bisser, MD, PhD, Centre International de Recherches Médicales de Franceville (CIRMF), BP 769 Franceville, Gabon.

Dominique Mazier, MD, PhD, INSERM U511, Immuno-Biologie Cellulaire et Moléculaire des Infections Parasitaires, Centre Hospitalier Universitaire Pitié-Salpêtrière, 91 Bd de l'Hôpital, 75013 Paris, France. 